\title{
Measuring the Market Power of the Portuguese Milk Industry
}

\author{
MARGARIDA DE MELLO and ANTÓNIO BRANDÃO
}

ABstract This paper is based on the previous work of Appelbaum (Fournal of Econometrics, 1979, 9, pp. 283-94; 1982, 19, pp. 287-99). Iwata (Econometrics 1974, 42, pp. 947-66) and Rogers (PhD Dissertation, GeorgeWashington University, 1983).We estimate the degree of market power of an oligopolistic industry, using a linear system and the 2SLS estimation method. Our departure point is the work of Appelbaum (1982) where a 'market power index' is estimated for each of the sample's 25 years. As the market power index depends functionally on the conjectural elasticity, the goal is to obtain annual estimates for that elasticity. For this purpose, Appelbaum defines a non-linear simultaneous-equation system and obtains, with non-linear methods, the conjectural elasticity estimates for each year of the sample. Considering the conjectural elasticity's functional form that Appelbaum adopts, we use a different approach and obtain a linear system that is easier to estimate. Due to the particular features of the industry analysed, we also derive a much simpler form for the equations involved. The model's simplicity is appealing and its generalisation to other industries with homogeneous products may be implemented with ease.

Key words: Oligopoly; Market power; Conjectural elasticity.

FEL classifications: L13, L66.

\section{Introduction}

Research on an industry requires knowledge of its features, environment and history. Familiarity with the so-called 'basic conditions' in which an industry operates is fundamental since it is desirable that such conditions are accurately reflected in a tractable economic model. This paper involves the estimation of the market power of the Portuguese milk industry. Because this industry's peculiarities play an important role in the model to be estimated, we find it advisable to first describe both the sector's evolution and its main features.

We are indebted for valuable comments from two anonymous referees that led to further significant improvement on this paper. The usual disclaimer applies. We would also like to express our thanks to William Collier and Gwyn Lewis for helping us with the editing.

António Brandão, Faculty of Economics, University of Porto Rua Dr Roberto Frias 4200 Porto, Portugal; e-mail<abrandao@fep.up.pt $>$. 
The milk industry has no tradition in Portugal. In spite of the importance of milk to human nutrition, its consumption became relevant only in the 1930s. In 1939, existing technology allowed only for the production of butter, Flemish cheese and dehydrated milk. At this time there were about 500 small firms, the majority of which had insufficient technical and hygienic conditions to assure the required minimum product quality. Lack of quality and the growing acquisition of cheese and butter from the Azores, did little to enhance the Portuguese mainland products, causing milk prices to suppliers to drop. This, combined with the insufficient supply of milk to larger cities caused the government to intervene and promote the concentration of the industry, shutting down the firms without adequate conditions, subsidising those which had them, and regulating the price paid to farmers. Exclusive supply areas to each manufacturing plant were also circumscribed. By 1944, the 54 plants that had survived were able to expand production and improve quality. However, this situation was short-lived. The continuation of World War II had seen the price of beef rise and the production of milk became secondary. Moreover, the plants' owners, shielded behind the exclusivity of their supply areas, acted against the farmers, paying them late and below the agreed price or even not collecting the milk at all. The farmers had no choice but to sell their cattle. Consequently, insufficient milk was supplied to the plants. This lack of raw materials brought anarchy into the industry and the government again had to intervene. In 1948, the government awarded the farmers' co-operatives the legal right to be the exclusive collectors of all the milk produced. No one else would have direct access to the raw materials. Non-co-operative firms had to buy the milk they needed from co-operatives. Soon, the co-operatives had their own plants and were able to assemble the majority of the farmers into three large cooperative firms that remain dominant today. These three firms partitioned the market, engaging in a territorial implicit agreement that allowed for their pacific coexistence for decades.

Except for certain kinds of cheese, the Portuguese demand for milk and related products had been supplied by the home industry-imports being irrelevant. Within this framework, the Portuguese milk industry flourished until the accession of Portugal to the EC in 1986. Due to the lack of competition, the milk sector was not prepared to compete in the open market. The Portuguese government achieved an agreement to delay the entrance of international competitors, promising the total liberalisation of the milk supply market (meaning the end of exclusive access to the raw materials for the co-operatives), until the 1 January 1989. Although this might have been a serious blow to the co-operatives, in the end, their dominance remained practically intact. The agreement linking the farmers to their co-operatives is of a symbiotic nature. The farmers promise to sell all their milk to the co-operatives and the co-operatives promise to buy it all, whatever the quantities or the quality. Additionally, the co-operatives supply veterinarian care to the farmers' cattle, technical and hygienic advice and financial aid. The price paid to the farmers for their product reflects this understanding and is negotiated every season.

When the Portuguese milk market opened up to foreign competition in 1993, there were 90 co-operative plants, the majority linked to the 'big three', and 50 nonco-operative plants. In 1992, the 'big three' represented $70 \%$ of the total milk collected, $80 \%$ of the total UHT (Ultra High Temperature) milk produced, $75 \%$ of all butter and $25 \%$ of other milk products. Upon deregulation, the farmers were offered higher prices for their milk by the new foreign competitors, but the farmers proved reluctant to change, rejecting the higher prices in favour of their previous bargain. This perpetuated the co-operatives control over raw materials. ${ }^{1}$ 
It was only in September 1993 that the Italian multinational Parmalat began to sell its milk in Portuguese supermarkets with a price that was a threat to the establishment. In a few months, Parmalat conquered an important share of the market and the 'big three' began to worry. The so-called 'milk war' had started and for months the press and television had something new to add. The 'big three' accused Parmalat of illegal dumping and predatory prices. The Italians accused the Portuguese of collusion and monopsonist dominance. Since 1991, merger rumours of the 'big three' had been spreading but it was only with the entrance of Parmalat and its visible success that the negotiations gained credibility and, in 1995, ended with the integration of the 'big three' into a 'big one'. ${ }^{2}$

The opinion in some business circles was that the easy entrance of Parmalat was due to the non-competitive behaviour of the domestic firms. The assumption was that domestic firms were shielded under informal collusion and governmental protection, and this explained the higher prices of their products. However, until now, there does not appear to have been any systematic investigation of these issues or any formal proof of collusive behaviour. In trying to clarify this, we decided to obtain an estimate of the Portuguese milk industry's degree of competitiveness before the full opening of the market. This estimate was obtained by analysing the period between 1963 and 1991.

\section{The Basic Model $^{3}$}

Appelbaum (1982), defines a non-linear simultaneous-equation system with a market demand function, three factor demand equations and an equilibrium condition written as:

$$
p(1-\theta E)=C M(\mathbf{W})
$$

Where $p$ is the product price, $E$ is the inverse of the demand elasticity, $C M$ is the marginal cost, $\mathbf{W}$ is the factor prices vector and $\theta$ is the conjectural elasticity, a nonobservable variable. If we estimate the system as defined above, $\theta$ will not vary over time. Since conjectural elasticity cannot be constant, Appelbaum solves the problem by defining $\theta$ as: ${ }^{4}$

$$
\theta_{t}=A_{\mathrm{O}}+A_{K} W K_{t}+A_{L} W L_{t}+A_{M} W M_{t}
$$

Here, $W K, W L$ and $W M$ are the prices of capital, labour and materials, respectively. Substituting (b) for $\theta$ in (a), Appelbaum obtains, with non-linear methods, estimates of the parameters $A_{\mathrm{O}}, A_{K}, A_{L}$, and $A_{M}$. These parameters provide the basis by which the author estimates the annual conjectural elasticity.

The linear dependence suggested in (b) (although overcoming the fact that $\theta$ is a non-observable variable) appears to be somewhat restrictive since conjectural elasticity depends upon the market shares and the conjectural variations, ${ }^{5}$ that is, the firms' expectations about the effects that changes in their production have on the output levels of their rivals. Given technology and assuming optimising behaviour, it is conceivable that firms' choices concerning the level of output as a strategic variable should include the market conditions. These conditions are associated with multiple and laborious aspects such as the degree of concentration, 
the type and level of entrance barriers, the legal and institutional framework surrounding the industry, the implicit or explicit agreements firms are engaged in, the diversification and substitutability of the products and the demand expansion or retraction cycles, amongst others. All of these may explain the way oligopoly members speculate about their rivals' moves and each serves to weaken equation (b) as an accurate explanation of the conjectural elasticity. Although existing theories are not explicit as to how such speculations are inserted into tractable empirical models, ${ }^{6}$ the problem of omitted variable bias (namely, those related with the downstream market conditions) and the suggested form for the dependence relation, impose limitations on the approach of Appelbaum. We therefore adopt a different approach, paying attention to both the main downstream and the upstream variables that affect conjectural elasticity.

We present the basic model below, displaying only the more representative equations. The main features of the model and its formal derivation are consigned to the appendix.

Suppose an oligopolistic industry with $n$ firms producing a homogeneous product using $m$ production factors. Taking firm $j$ and solving for its maximisation problem we obtain the following equation:

$$
p\left(1-\theta_{j} E\right)=C M_{j}
$$

where $p$ is the market price, $\theta_{j}$ is firm $j$ 's conjectural elasticity, $E$ is the inverse of the demand elasticity ( $\varepsilon$ being that elasticity) and $C M_{j}$ is firm $j$ 's marginal cost.

We can define the degree of the industry's market power such that,

$$
L r=\sum_{j} \frac{p-C M_{j}}{p} \cdot s_{j}=\sum_{j} \theta_{j} E s_{j}
$$

where $s_{j}$ is firm $j$ 's market share.

Lack of data at the firm level restricts us to the basic model's aggregate form. This is presented in the next section, where only the key equations are again displayed. Formal derivation of the model is once more consigned to the appendix.

\subsection{The Aggregate Form of the Basic Model}

Assuming that the marginal costs are the same for all firms and that $\theta_{j}=\theta \forall$, equation (1) can be rewritten as. ${ }^{7}$

$$
p(1-\theta E)=C M
$$

and the market power measure of the industry will now be $L r=\theta E$. If the industry is perfectly competitive, $L r=0$. If the industry is a pure monopoly $L r=E$. Hence, both $\theta$ and $L r$ provide information about the industry's degree of competitiveness. Since we want an estimate of the industry's conjectural elasticity, we rewrite equation (3) as:

$$
\theta=\frac{p-C M(\mathbf{w})}{p} \cdot \varepsilon
$$


To reach the conjectural elasticity value in (4), we need to estimate the demand elasticity and the industry's marginal cost. To obtain these estimates we build a simultaneous equation model with a demand equation, three factor demand functions and an equilibrium condition. The equilibrium condition takes into account that, in an oligopoly, price need not necessarily equate to marginal cost. This allows for the possible existence of a positive margin.

In the next section we will present the aggregate model. First, we present the demand equation then the conditional factor demands and finally the equilibrium relation.

\subsubsection{The Demand Equation. Several phenomena influenced the Portuguese milk} industry during the sample period and some of them had a significant impact on product demand. The mid-1970s saw the technological innovation of UHT packed milk introduced to the distribution circuits. ${ }^{8}$ UHT milk does not require refrigeration and subsequently allows for prolonged storage. This has permitted changes in the buying periodicity which favoured consumption. The free distribution of milk in Portuguese schools, undertaken by the government since 1974 presents another important point regarding product demand. The long advertising campaign (1987-93), financed by the milk producers' confederation, the Portuguese government and the EC authorities which promoted the slogan 'milk is youth' provides another. Assuming the effects of each of these to be manifest in the same direction, and that they have been only relevant since 1977, we establish the possible change of consumers' behaviour through a dummy variable $D L$, included in the demand equation. ${ }^{9}$ We additionally posit changes in the price elasticity of demand to be possible over the sample period. To allow for this possibility we insert two additional dummy variables in the demand equation, separating the three decades of the sample period. ${ }^{10}$ The demand equation is thus estimated as:

$$
\begin{aligned}
\ln Q= & \ln d_{\mathrm{O}}+\varepsilon \ln p+d_{1} \ln P I B+d_{2} D L+d_{3}\left(D_{1}{ }^{\star} \ln p\right) \\
& +\mathrm{d}_{4}\left(\mathrm{D} 2^{\star} \ln p\right)+v_{1}
\end{aligned}
$$

Where $p$ is the market price of milk at period $t$ in constant (1990) escudos, $Q$ is the milk consumption at period $t$ in millions of litres, and PIB is the Portuguese Gross Domestic Product at period $t$, in constant (1990) $10^{9}$ escudos. The dummy variables are such that, $D 1=1$ if $t \in[1962,1970]$ and $D 1=0$ otherwise, $D 2=1$ if $t \in[1971,1980]$ and $D 2=0$ otherwise, $D L=1$ if $t \in[1977,1992]$ and $D L=0$ otherwise. The disturbance term $v_{1}$ is assumed to be well behaved.

2.1.2. The Factor Demand Equations. The main industry inputs are raw materials $(M)$, capital $(C)$ and labour $(L)$. These three inputs stand for more than $90 \%$ of the total cost. Raw materials alone (essentially milk) account for more than $70 \%$. Assuming a Generalised Leontieff Cost Function for this industry, we write the industry cost function in the following form:

$$
\begin{aligned}
C(Q, \mathbf{w})= & b_{C} w_{C}+b_{L} w_{L}+b_{M} w_{M}+\left[b_{C C} w_{C}+b_{L L} w_{L}+b_{M M} w_{M}\right. \\
& \left.+2 b_{C L}\left(w_{C} w_{L}\right)^{1 / 2}+2 b_{C M}\left(w_{C} w_{M}\right)^{1 / 2}+2 b_{L M}\left(w_{L} w_{M}\right)^{1 / 2}\right] Q
\end{aligned}
$$


Since the aggregate factor demand functions for the industry are given by

$$
f_{i}=\frac{\partial C(Q, \mathbf{w})}{\partial w_{i}},
$$

with $i=M, C, L$, we have:

$$
\begin{aligned}
& \frac{\partial C(Q, \mathbf{w})}{\partial w_{C}}=\frac{f_{C}}{Q}=b_{C} \frac{1}{Q}+b_{C C}+b_{C L}\left(\frac{w_{L}}{w_{C}}\right)^{1 / 2}+b_{C M}\left(\frac{w_{M}}{w_{C}}\right)^{1 / 2} \\
& \frac{\partial C(Q, \mathbf{w})}{\partial w_{L}}=\frac{f_{L}}{Q}=b_{L} \frac{1}{Q}+b_{L L}+b_{C L}\left(\frac{w_{C}}{w_{L}}\right)^{1 / 2}+b_{L M}\left(\frac{w_{M}}{w_{L}}\right)^{1 / 2} \\
& \frac{\partial C(Q, \mathbf{w})}{\partial w_{M}}=\frac{f_{M}}{Q}=b_{M} \frac{1}{Q}+b_{M M}+b_{C M}\left(\frac{w_{C}}{w_{M}}\right)^{1 / 2}+b_{L M}\left(\frac{w_{L}}{w_{M}}\right)^{1 / 2}
\end{aligned}
$$

The Portuguese milk industry produces a multitude of diversified products besides plain milk. Since observable data reflect only the industry level, we were not able to gather sufficient information to build an input-output table. The available data provide information about the total quantity of processed milk (as an input), the total amount of packed milk produced and the total number of tons of all other products. Additionally, we have the total cost of all the milk processed, the total labour hours used in production and the cost of labour per hour, the total amount of capital included and the cost per capital unit, and the milk price per litre paid to suppliers. This information does not permit calculation of the required amount of milk to produce one litre of packed milk. We therefore assume that it is necessary to use one litre of plain milk as an input to produce one litre of packed milk. If this assumption is acceptable, then the cost of one unit of packed milk is equal to the cost of transforming that unit of milk. As the production factors in one milk packet are labour, capital and milk, and since we know the cost of labour and capital per manufactured litre and the cost of milk per unit, the cost of one litre of packed milk is, given this assumption, exactly the cost of processing that litre of milk. ${ }^{11}$ Since in equations (7)-(9) we are now dealing with costs of produced milk and not the cost of milk supplied to the market, we substitute $Q$ with the variable $P R M$, that is, the total amount of milk processed by the industry each year. ${ }^{12}$ There are additional consequences from this assumption. For instance, in equation (9), parameter $b_{M M}$ will now be $1, \forall t$, and all the other parameters in that equation will be zero. ${ }^{13}$ Given these changes, equations (7)-(9) will now be:

$$
\begin{aligned}
& \frac{f_{C}}{P R M}=b_{C C}+b_{C} \frac{1}{P R M}+b_{C L}\left(\frac{w_{L}}{w_{C}}\right)^{1 / 2} \\
& \frac{f_{L}}{P R M}=b_{L L}+b_{L} \frac{1}{P R M}+b_{C L}\left(\frac{w_{C}}{w_{L}}\right)^{1 / 2} \\
& \frac{f_{M}}{P R M}=1
\end{aligned}
$$


2.1.3. The Equilibrium Condition. As we are dealing with an oligopoly we have to acknowledge the possible existence of a positive margin in the model. Suppose the following equilibrium equation: ${ }^{14}$

$$
p\left(1-m^{\prime}\right)=\frac{\partial C(P R M, \mathbf{w})}{\partial P R M}
$$

where

$$
\begin{aligned}
\frac{\partial C(P R M, \mathbf{w})}{\partial P R M}= & b_{C C} w_{C}+b_{L L} w_{L}+b_{M M} w_{M}+2 b_{C L}\left(w_{C} w_{L}\right)^{1 / 2} \\
& +2 b_{C M}\left(w_{C} w_{M}\right)^{1 / 2}+2 b_{L M}\left(w_{L} w_{M}\right)^{1 / 2}
\end{aligned}
$$

is the industry's marginal cost, and $m^{\prime}$ is an alternative form for the mark-up, being $0 \leq m^{\prime} \leq 1 .^{15}$

Since $m^{\prime}$ depend on both the market price and the marginal cost, and since the marginal cost depends, essentially, on the factor price vector $\mathbf{w}$, it seems possible to consider $m^{\prime}$ as depending on $p$ and $\mathbf{w}$, such that $m^{\prime}=g(p, \mathbf{w})$, is approximately given by an equation with the following form. ${ }^{16}$

$$
\begin{aligned}
& m^{\prime}=\alpha_{C} \frac{w_{C}}{p}+\alpha_{L} \frac{w_{L}}{p}+\alpha_{M} \frac{w_{M}}{p} \text { or } \\
& m^{\prime}=\frac{1}{p}\left(\alpha_{C} w_{C}+\alpha_{L} w_{L}+\alpha_{M} w_{M}\right)
\end{aligned}
$$

Substituting (11) into (10) and assuming, as above, that $b_{C M}=b_{L M}=0$, we have:

$$
\begin{aligned}
p= & \left(\alpha_{C}+b_{C C}\right) w_{C}+\left(\alpha_{L}+b_{L L}\right) w_{L}+\left(\alpha_{M}+b_{M M}\right) w_{M} \\
& +2 b_{C L}\left(w_{C} w_{L}\right)^{1 / 2}
\end{aligned}
$$

An alternative and more elaborate approach towards the estimation of the conjectural elasticity is provided by Appelbaum (1982). The approach inherent in equation (11) has the advantage of making the empirical estimation of the model easier and is particularly applicable to the industry under consideration.

Hence, the complete system to be estimated is given by equations (13)-(17):

$$
\begin{aligned}
& \begin{aligned}
\ln Q= & \ln d_{\mathrm{O}}+\varepsilon \ln p+d_{1} \ln P I B+d_{2} D L+d_{3}\left(D 1^{\star} \ln p\right) \\
& +d_{4}\left(D 2^{\star} \ln p\right)+v 1
\end{aligned} \\
& \begin{aligned}
\frac{f_{C}}{P R M}= & b_{C C}+b_{C} \frac{1}{P R M}+b_{C L}\left(\frac{w_{L}}{w_{C}}\right)^{1 / 2}+v 2
\end{aligned} \\
& \frac{f_{L}}{P R M}=b_{L L}+b_{L} \frac{1}{P R M}+b_{C L}\left(\frac{w_{C}}{w_{L}}\right)^{1 / 2}+v 3 \\
& \frac{f M}{P R M}=1 \\
& \begin{aligned}
p= & \left(\alpha_{C}+b_{C C}\right) w_{C}+\left(\alpha_{L}+b_{L L}\right) w_{L}+\left(\alpha_{M}+b_{M M}\right) w_{M} \\
& +2 b_{C L}\left(w_{C} w_{L}\right)^{1 / 2}+v 5
\end{aligned}
\end{aligned}
$$


The variables $Q, P R M, p, f_{r}, f_{C}$ and $f_{M}$, are endogenous, all the others being exogenous. Equations $13-15$ and 17 are stochastic because of optimisation errors so, period $t$ disturbance terms in each of these equations is $v(i)$ where $i=1 \ldots, 4$

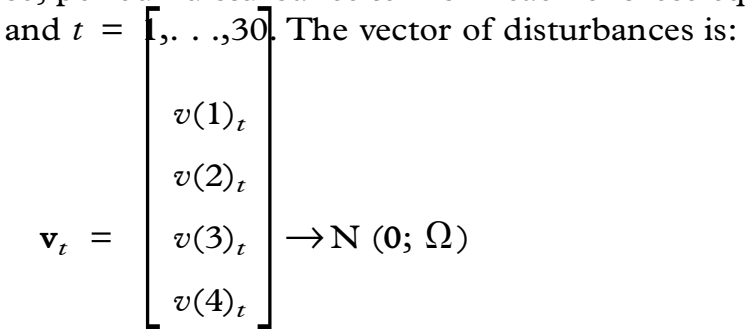

where the variance and covariance matrix $\Omega$ is non-singular and such that:

$$
\begin{aligned}
E\left[v(i)_{t} \cdot v(j)_{t}\right] & =\sigma_{\mathbf{I}}^{2} & \text { if } i=j \\
& =0 & \text { if } i \neq j \quad \text { and } i, j=1, \ldots, 4 \\
E\left[v(i)_{t} \cdot v(j)_{t-s}\right] & =0 & \text { if } s \neq 0, \quad \forall i, j
\end{aligned}
$$

Equation (17) depends exclusively on exogenous variables. If it is assumed that the quantity of milk produced is unrelated to the quantity of milk demanded, then equation (13) will be independent of any other equations in the system. This assumption seems reasonable given the characteristics of the industry mentioned earlier, namely that the co-operatives were, until 1989, the exclusive buyers of the farmers' milk. Although this legal advantage has been lost in recent years, the cooperatives remain responsible for the majority of milk collection. Milk collected by other firms is manifestly insufficient since they systematically depend on the surplus of the co-operatives for their unfulfilled needs. It is also known that the co-operatives have the obligation of collecting all the milk their suppliers produce, regardless of its quantity or quality. Hence, we must conclude that all the milk produced by the farmers is collected by the firms. The milk is brought to the plants and transformed into several products. The milk surplus of the cooperatives, not sold to other firms, will also be transformed, either by being submitted to a drying process or changed into butter (the only ways of storing milk). It seems possible to presume therefore that all the milk collected is changed either into vendible or into storable products. Hence, the milk quantity processed by the industry will have more to do with the amount supplied by the farmers than with the amount consumed by the market. Equally, it seems reasonable to assume independence between the milk quantity processed by the industry and the milk quantity bought by the Portuguese. This being true, equation (13) can be estimated independently, with OLS, whilst the others must be estimated simultaneously, with 2 SLS. The system of equations displayed above is, then, a recursive one.

\section{The Estimation Statistical Results}

The results obtained for equation (13) are as follows:

$$
\ln Q=\underset{(0.0600)}{3.461}-\underset{(0.1053)}{0.2597 \ln p}+\underset{(0.0804)}{0.9153 \ln P I B}+\underset{(0.0402)}{0.0786 D}+\underset{(0.0151)}{0.0441}\left(D 1^{\star} \ln p\right)
$$


$+\underset{(0.0101)}{0.0169(D 2 \star \ln p)}$

$$
R^{2}=0.98 \quad F=229 \quad D W=2.29
$$

where the figures in parentheses are the standard errors. These results confirm demand elasticity variability. In the period $1962-70$, the elasticity estimate is -0.22 , in the period $1971-80$, it is -0.24 and, in the period $1981-91$ it is -0.26 . The simultaneous estimation results of equations (14), (15) and (17), are the following:

$$
\begin{aligned}
& \frac{f_{C}}{P R M}=\underset{(0.4463)}{-1.8845}-\underset{(102.404)}{54.6725} \frac{1}{P R M}+\underset{(0.01153)}{0.133146}\left(\frac{w_{L}}{w_{C}}\right)^{1 / 2}, \\
& R^{2}=0.894, \quad F=114 \\
& \frac{f_{L}}{P R M}=\underset{(0.00092)}{0.008045}+\underset{(0.36243)}{2.37574} \frac{1}{P R M}+\underset{(0.01153)}{0.133146}\left(\frac{w_{C}}{w_{L}}\right)^{1 / 2}, \\
& R^{2}=0.899, \quad F=120 \\
& \hat{p}=\underset{(5.6431)}{-10.7473 w_{C}}-\underset{(0.01876)}{0.04893 w_{L}}+\underset{(0.08869)}{1.63613 w_{M}}+\underset{(0.01153)}{0.133146}\left[2\left(w_{C} w_{L}\right)^{1 / 2}\right], \\
& R^{2}=0.991, \quad F=747
\end{aligned}
$$

Using the estimates of $b_{C C}$ as $-1.8845, b_{L L}$ as 0.008045 and $b_{C}$ as 0.133146 , we estimated the values of the industry's marginal cost over the thirty years of the sample. With these values and the demand elasticity estimates, we obtained the conjectural elasticity and the market power index estimates. The market price and the estimates of the marginal cost, market power index and conjectural elasticity are shown in Table 1.

Table 1 shows that all the estimated values for the conjectural elasticity and the market power index are positive, which identifies an imperfectly competitive market structure and the presence of market power. However, those estimates must be significantly above zero to allow for more definite conclusions. To test the relevant hypotheses for the presence of perfect competition and the absence of market power, we used the sample mean estimates of $\theta$ and $L r$ and their standard deviations shown below:

Sample Mean Estimates

\begin{tabular}{lcc}
\hline & $\overline{\hat{\lambda}}$ & $\overline{\mathbf{L}}$ \\
& & \\
\hline Estimates & 0.05403 & 0.22900 \\
Estimate Standard Deviations & 0.02345 & 0.10573 \\
\hline
\end{tabular}

For a $5 \%$ level of significance, the perfect competition hypotheses $\left(H_{\mathrm{O}}: \theta=0\right)$ is rejected with the $t$ statistic sample value 2.304. The absence of market power hypothesis $\left(H_{O}: L r=0\right)$ is also rejected with the $t$ statistic sample value of 2.167 . 
Table 1. The market price and the estimated values for the marginal cost, market power index, and conjectural elasticity of the Portuguese milk industry

\begin{tabular}{|c|c|c|c|c|}
\hline & Market price & $\hat{C} M_{t}$ & $\hat{L}_{r}$ & $\hat{\theta}_{t}$ \\
\hline 1962 & 113.60 & 61.53 & 0.458 & 0.101 \\
\hline 1963 & 111.54 & 61.57 & 0.448 & 0.099 \\
\hline 1964 & 107.15 & 62.53 & 0.416 & 0.092 \\
\hline 1965 & 108.28 & 65.93 & 0.391 & 0.086 \\
\hline 1966 & 106.45 & 63.88 & 0.400 & 0.088 \\
\hline 1967 & 103.49 & 67.72 & 0.346 & 0.076 \\
\hline 1968 & 102.26 & 67.08 & 0.344 & 0.076 \\
\hline 1969 & 97.57 & 66.50 & 0.318 & 0.070 \\
\hline 1970 & 93.08 & 64.79 & 0.304 & 0.067 \\
\hline 1971 & 89.29 & 63.46 & 0.289 & 0.069 \\
\hline 1972 & 86.52 & 65.05 & 0.248 & 0.060 \\
\hline 1973 & 85.60 & 65.12 & 0.239 & 0.057 \\
\hline 1974 & 80.00 & 60.70 & 0.241 & 0.058 \\
\hline 1975 & 85.07 & 66.38 & 0.220 & 0.053 \\
\hline 1976 & 83.52 & 62.30 & 0.254 & 0.061 \\
\hline 1977 & 81.47 & 67.40 & 0.173 & 0.042 \\
\hline 1978 & 78.32 & 70.95 & 0.094 & 0.023 \\
\hline 1979 & 76.71 & 68.93 & 0.101 & 0.024 \\
\hline 1980 & 72.82 & 61.18 & 0.160 & 0.038 \\
\hline 1981 & 73.89 & 63.89 & 0.135 & 0.035 \\
\hline 1982 & 75.51 & 63.57 & 0.158 & 0.041 \\
\hline 1983 & 84.17 & 64.51 & 0.234 & 0.061 \\
\hline 1984 & 95.51 & 67.77 & 0.290 & 0.076 \\
\hline 1985 & 104.44 & 70.06 & 0.329 & 0.086 \\
\hline 1986 & 101.18 & 68.95 & 0.319 & 0.083 \\
\hline 1987 & 100.17 & 66.36 & 0.338 & 0.088 \\
\hline 1988 & 98.58 & 63.05 & 0.361 & 0.094 \\
\hline 1989 & 105.24 & 61.36 & 0.417 & 0.108 \\
\hline 1990 & 109.22 & 56.30 & 0.485 & 0.126 \\
\hline 1991 & 104.88 & 49.14 & 0.532 & 0.138 \\
\hline
\end{tabular}

Therefore, both tests are consistent with the presence of market power and an imperfectly competitive market structure.

With the figures for estimates of $M C, \theta$ and $L r$ provided in Table 1 , we can ask if they present a coherent picture of the industry and whether we should just look at the overall average or pay attention to sub-period trends or even individual values. Although the overall average trend can give some explanation about the behaviour of the industry along the 30 years of the sample there are other interesting features we should pay attention to. For instance, we should point out two distinguishable periods in Table 1 where important events lead to some upheaval in the milk sector: first; the period between 1975 and 1979, following the revolution of April 1974 when democracy was attained nationally; second, the period between 1986 and 1991 following the accession of Portugal to the EC.

The first period is characterised by left-wing government legislation protecting the co-operatives and reinforcing their role in the industry. In this period, milk production rose $13.5 \%$, on average, per year as consumption grew sharply. The number of co-operatives linked to the 'big three' increased whilst the implicit agreement of market partition took place. The market price of milk fell due to 
government subsidies designed to support growing demand and implant a durable habit of milk consumption among the Portuguese population. The co-operatives were faced with agreeing to higher prices and further technical aid to farmers in response to the increase in demand. The average wage of the manufacturing sector also rose sharply between 1974 and 1978 with the introduction of the minimum wage and higher wage claims from the recently formed unions. Higher input prices combined with the use of obsolete production techniques justify the marginal cost growth we observe in Table 1 .

The second period relates to the threat of new competitors entering the domestic market following the accession of Portugal to the EC. The immediate results of Portuguese accession were that milk prices paid to the farmers should equalise EC prices ${ }^{17}$ and that liberalisation of the milk supply market should take place. While the prices paid to the farmers rapidly attained stagnation, the liberalisation of the milk supply market was only fully completed by 1 January 1989. The co-operatives had time to invest strongly, and did so, not only in new production techniques but also in the improvement of pasturage, cattle artificial insemination, modern milking facilities and more rational and cheaper ways of collecting the milk from their suppliers. In 1989, upon deregulation of the supply market, the co-operatives could verify that the loss of their previous legal privilege had little effect on their dominant position. Anticipating the strong competition they would have to endure from 1990 onwards, and relying upon their dominant position in the supply market, the co-operatives increased the price to consumers, in an attempt to obtain as much profit as possible before the entry of new firms. The year of 1990 went by and no new firms were installed. The co-operatives knew that new entrants would find it difficult to obtain raw materials and, relying upon this advantage, increased the market price of milk further. Only in 1993 did Parmalat start selling its products in the Portuguese domestic market, triggering the so-called 'milk war'. Between 1993 and 1994 the co-operatives lost a market share of around $12 \%$ to Parmalat while the market price fell by approximately $7 \%$. The response of the co-operatives was to merge. This was fully accomplished in January 1997.

\section{Conclusion}

Taking Appelbaum (1982) as a departure point, we estimated the degree of competitiveness of the Portuguese milk industry in the period before the market was fully open to foreign competition. Due to both the peculiarities of this industry and the different approach we used to define conjectural elasticity, we were able to obtain a simultaneous linear equation system that was easier to estimate. Since our hypothesis was that a constant demand elasticity over the sample's 30 years was improbable, we allowed for its variability by adding two dummy variables to the demand function. ${ }^{18}$ However, if a linear demand equation had been used instead of a Cobb-Douglas, a changing demand elasticity could be derived from the demand equation without additional variables.

The motive for this work appeared when a huge debate, known as 'the milk war', arose in Portugal during 1993. The central issue of this debate was the easy way in which foreign firms entered the Portuguese milk market. Some critics sustained that the entrants' success was due to a long practice of market power exploitation by domestic firms. Others believed that the practice of predatory prices and illegal 
dumping by foreign firms was to blame. The degree of market power underlies both such claims. Thus, measuring the market power of the industry appeared important, if one wanted to hold a valid opinion.

Our results corroborate the presence of an imperfectly competitive market structure and the exploitation of market power by domestic firms. These results were expected since they prove compatible with detectable signs of collusive behaviour. These signs include the governmental protection awarded to cooperatives for decades; their implicit territorial agreement; a low milk demand elasticity (confirmed through the estimates obtained); the concerted actions of cooperatives concerning the advertising of their main product; control over raw materials and, finally, merger negotiations initiated as the market was opened.

There is not, at present, sufficient information to examine, in detail, the events following the merger of the 'big-three' but we can confirm from data currently available that Parmalat lost roughly $5 \%$ of its previously conquered market share. Further research on this issue can be undertaken as soon as more data become available.

\section{Notes}

1. 'Oligopsony' is not an accurate concept to describe this situation. The link between the farmers and the co-operatives has more to do with mutual trust than with merely commercial interests. Although farmers and co-operatives are different legal entities, their historical and contractual bonds support a complex structure that could classify the industry as vertically integrated.

2. The 'big three' merger negotiations contemplated two steps. The first, completed in January 1995, concerned only the distribution and the milk collecting circuits. The second, finished in January 1997, concerned the production process.

3. This basic model follows that of Appelbaum (1982), although the way in which it is derived could be found with other authors, namely Iwata (1974) and Rogers (1983).

4. See Appelbaum (1982: 293): 'In general, $\theta$ will not be constant but a function of various relevant variables.'

5. If we consider the aggregate model, the conjectural elasticity will depend on the price-cost margin and on the demand elasticity. Either way, the conjectural elasticity depends on the market conditions: upstream, by the factor prices and, downstream, by the product price, market shares and demand elasticity.

6. Even if they were explicit, the obstacles that inevitably would appear, related to the data collection on the multiplicity of variables involved, would be difficult to overcome.

7. We follow Appelbaum's argument '. . . it is clear that, if marginal costs are the same for all firms then, in equilibrium, the conjectural elasticities must be the same as well' Appelbaum (1982: 292).

8. The technological innovation of UHT milk had more impact on the demand side than on the supply side as the costs of change in production process seemed negligible. UHT milk only requires a new kind of packaging and to be heated to higher temperatures and for longer than other types of milk (for example, pasteurised milk).

9. Although initiated in 1974, the school milk programme only covered a significant number of pupils in the school year $1976 / 77$. We also had to consider that the UHT milk weight in the total milk consumption was already $15 \%$ in 1978 , reaching $70 \%$ in 1990 . Consequently, concerning the dummy variable $D L$, we divided the sample period in two: before 1977 and thereafter.

10. We tried alternative sub-periods but those we selected guaranteed the best results.

11. Suppose, for example, that we have $1000 \mathrm{~L}$ of milk and that $5000 \mathrm{esc}$ is the cost of transforming that quantity of milk into $10 \mathrm{~kg}$ of cheese, $5 \mathrm{~kg}$ of butter and $300 \mathrm{~L}$ of packed milk. Given this assumption, we know that, to produce $300 \mathrm{~L}$ of packed milk, we need $300 \mathrm{~L}$ of milk, and the total transformation cost associated is 1500 esc. We ignore the quantity of milk necessary to produce $1 \mathrm{~kg}$ of cheese or $1 \mathrm{~kg}$ of butter but we can say that 7001 of milk are necessary to produce $10 \mathrm{~kg}$ of cheese and $5 \mathrm{~kg}$ of butter, and we can add that the total production cost of those goods is 3500esc.

12. This new variable $P R M$ will now substitute the variable $Q$ in every equation that concerns the supply side of the model. 
13. This is plausible since the quantity of milk used to produce one litre of packed milk does not seem to depend on the price of milk when related to those of labour or capital. Whatever these prices are, the quantity of milk used to obtain $1 \mathrm{~L}$ of packed milk will depend, exclusively, on the technical production process. So, it seems impossible to substitute the milk factor for any other factor, even if their prices were relatively lower. The possible variability of input-output coefficients should not affect packed milk since it is our belief that, to produce $1 \mathrm{~L}$ of packed milk, $1 \mathrm{~L}$ of inputed milk will always be needed. We also assume efficient production and, in this case, the tendency to waste should be zero.

14. A similar assumption, but using the mark-up definition in a slightly different way, can be found in Rogers (1983).

15. The mark-up is often considered to be some quantity above the unitary cost that is usually expressed by the equation $p=(1+m) C M$. This mark-up, $m$, is based on cost and ranges from $[0, \infty]$. So, considering costs as strictly positive, if $C M=p$, then, $m=0$ and if $C M \rightarrow 0$, then, $m \rightarrow \infty$. In our view, we look at price instead of cost to define 'mark-up' $m$ '. We could call it 'mark-down', for we make use of the fact that the unitary cost is, generally, a fraction of the price. Consequently, $m^{\prime}$ ranges from $[0,1]$ since, if $C M>0 \Rightarrow p\left(1-m^{\prime}\right)>0 \Rightarrow\left(1-m^{\prime}\right)>0 \Rightarrow m^{\prime}<1$ and if $p \geq C M \Rightarrow$ $p \geq p\left(1-m^{\prime}\right) \Rightarrow 1 \geq 1-m^{\prime} \Rightarrow m^{\prime} \geq 0$.

16. As mentioned in note 7, Appelbaum (1982: 293) claims that the conjectural elasticity depends on various relevant variables and states also that '... its equilibrium value, as can be seen from equation (13), will depend on the exogenous variables'. Appelbaum's equation (13) is $p(1-\theta E)=C(\mathbb{W})$ and, based on it, Appelbaum assumes that $\theta$ could be approximated by the linear function $\theta=A_{\mathrm{O}}+$ $A_{\mathrm{K}} W_{K}+A_{L} W_{L}+A_{M} W_{M}$. As we see it, even taking into consideration Appelbaum's equation (13) alone, $\theta$ depends not only on the exogenous variables but also on an endogenous one, $p$.

17. In Appelbaum's model, changes of the demand elasticity over time are not taken into consideration. We assume variability of the milk demand elasticity and our estimates confirm that is not advisable to overlook this issue.

18. Portuguese milk prices to suppliers were greater than the EC prices in 1986.

\section{References}

Appelbaum, E., 'Testing Price-taking Behaviour,' fournal of Econometrics, 1979, 9, pp. 283-94.

Appelbaum, E., 'The Estimation of the Degree of Oligopoly Power,' Fournal of Econometrics, 1982, 19, pp. 287-99.

Iwata, G., 'Measurement of Conjectural Variations in Oligopoly,' Econometrica, 1974, 42(5), pp. 947-66.

Rogers, R., 'The Behaviour of Firms in a Oligopolistic Industry. A Study of Conjectural Variations,' Unpublished Ph.D. Dissertation, George Washington University, May 1983.

\section{Appendix}

\section{The Basic Model}

Suppose an oligopolistic industry with $n$ firms producing a homogeneous product using $m$ production factors. Let the cost function of firm $j$ be:

$$
C_{j}=C_{j}\left(q_{j}, \mathbf{w}\right)
$$

where $q_{j}$ is firm $j$ 's output and $\mathbf{w}$ is the factor prices vector.

Let also the market demand function be:

$$
Q=D(p, \mathbf{V})
$$

of which derivative with respect to the market price $p$ is supposed to be negative for all $p>0$. In equation (A2), $Q$ is the total industry output, such that $Q=\sum q_{j}$ is the industry supply, and $\mathrm{V}$ is a vector of exogenous variables that affect demand. Assuming maximising behaviour and defining firm $j$ 's profit as $\Pi_{\mathrm{j}}=R_{j}-C_{j}$ where $R_{j}$ and $C_{j}$ are, respectively, firm $j$ 's total revenue and total cost, its profit maximising problem is:

$\operatorname{Max}\left[p q_{j}-C\left(q_{j}, \mathbf{w}\right)\right.$, subject to $\left.Q=\mathbf{D}(p, \mathbf{V})\right]$ 
The first order condition for this problem's solution requires that firm $j$ 's marginal revenue $\left(R M_{j}\right)$ equals its marginalcost $\left(C M_{j}\right)$. Consequently, we have the equation:

$$
p\left(1-\theta_{j} E\right)=C M_{j}
$$

Where $\theta_{j}$ is the firm $j$ conjectural elasticity concerning the industry output such that:

$$
\begin{aligned}
\theta_{j} & =\frac{\mathrm{d} Q}{\mathrm{~d} q_{j}} \frac{q_{j}}{Q}=\left(\frac{\mathrm{d} q_{i}}{\mathrm{~d} q_{j}}+\ldots+\frac{\mathrm{d} q_{i}}{\mathrm{~d} q_{j}}+\ldots+\frac{\mathrm{d} q_{n}}{\mathrm{~d} q_{j}}\right) \frac{q_{i}}{Q}=\left(1+\sum_{k \neq j} \frac{\mathrm{d} q_{k}}{\mathrm{~d} q_{j}}\right) \frac{q_{j}}{Q} \\
& =\left(1+\gamma_{j}\right) \frac{q_{j}}{Q}
\end{aligned}
$$

where $\gamma_{j}=\sum_{k \neq j} \frac{\mathrm{d} q_{k}}{\mathrm{~d} q_{j}}$ is firm $j$ 's conjectural variation and $\frac{q_{j}}{Q}=S_{j}$ is firm $j$ 's market share.

In equation (A5), the conjectural elasticity definition for firm $j$ (which includes both the market share and the conjectural variation), stands for the expected percentage change in firm $j$ rivals' outputs as a reaction to a $1 \%$ change in firm $j$ output. In the Cournot behaviour case, $\mathrm{d} Q / \mathrm{d} q_{j}=1$ (since $\mathrm{d} q_{k} / \mathrm{d} q_{j}=0, \forall k, j$; $k \neq j$ ), and $\theta_{j}$ will simply be the market share $\left(\theta_{j}=\mathrm{s}_{j}\right.$ ). In the perfect competition case, $\theta_{j}=0$ (since $\gamma_{j}$ $=-1$ ) and price equals the marginal cost. In the pure monopoly case, $\theta_{j}=1$, since there is only one firm implying $q_{j}=Q$ and $\mathrm{d} Q / \mathrm{d} q_{j}=1$. Hence, the monopoly price-cost margin equals the inverse of the demand elasticity.

Rewriting equation (A4) as

$$
\frac{p-C M_{j}}{p}=\theta_{j} E
$$

we can define the market power degree of firm $j$ as the Lerner index $l_{j}$ such that:

$$
l_{j}=\frac{p-C M_{j}}{p}=\theta_{j} E
$$

Multiplying both sides of equation (A6) by the market share $s_{j}$ and summing up over $j$, we will have the industry market power degree $L r$, such that:

$$
\sum_{j} l_{j} s_{j}=\sum_{j} \frac{p-C M_{j}}{p} \cdot s_{j}=\sum_{j} \theta_{j} E s_{j}=L r
$$

\section{The Aggregate Form of the Basic Model}

Assuming the usual aggregation condition that the marginal costs are the same for all firms and also assuming that $\theta_{j}=\theta$ for all $j$, equation (A4) can be rewritten as:

$$
p(1-\theta E)=C M
$$

Since $\theta_{j}=\theta$ and $\sum s_{j}=1$, the market power measure will now be $L r=\theta E$.

The estimate for the industry's conjectural elasticity, will be obtained from the equation (A8) rewritten as:

$$
\theta=\frac{p-C M(\mathbf{w})}{p} \cdot \varepsilon
$$

